\title{
Correction to: Surgical Approaches for Common Gynecologic and Obstetrics Surgeries
}

\section{Ahmed Samy El-Agwany ${ }^{1,2}$}

Published online: 8 February 2020

(C) Indian Association of Surgical Oncology 2020

\section{Correction to: Indian Journal of Surgical Oncology} https://doi.org/10.1007/s13193-019-00987-6

We, the authors, agree to the following changes on our manuscript (https://doi.org/10.1007/s13193-019-00987-6) entitled (Surgical Approaches for Common Gynecologic and Obstetrics Surgeries). Regarding changes in figure 1, 3. Also, we are adding a figure 4 for paragraph 5 after reference $(1,2)$.

The online version of the original article can be found at https://oi.org/ 10.1007/s13193-019-00987-6

\section{Ahmed Samy El-Agwany}

Ahmedsamyagwany@gmail.com;

ahmed.elagwany@alexmed.edu.eg

1 Department of Obstetrics and Gynecology, Faculty of Medicine, Alexandria University, Alexandria, Egypt

2 El-Shatby Maternity University Hospital, Faculty of Medicine, Alexandria University, Alexandria, Egypt

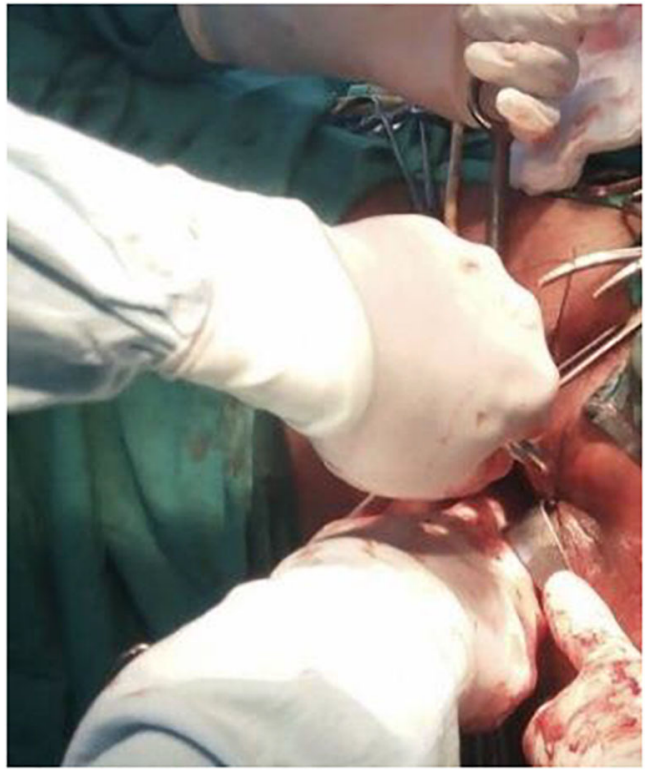

Figure 1 Hand direction with the needle holder technique for suturing through the ligament; holding the long holder with no fingers in the handle eyes for easy manipulation and rotation of the instrument with index and middle on one side and thumb on other side 

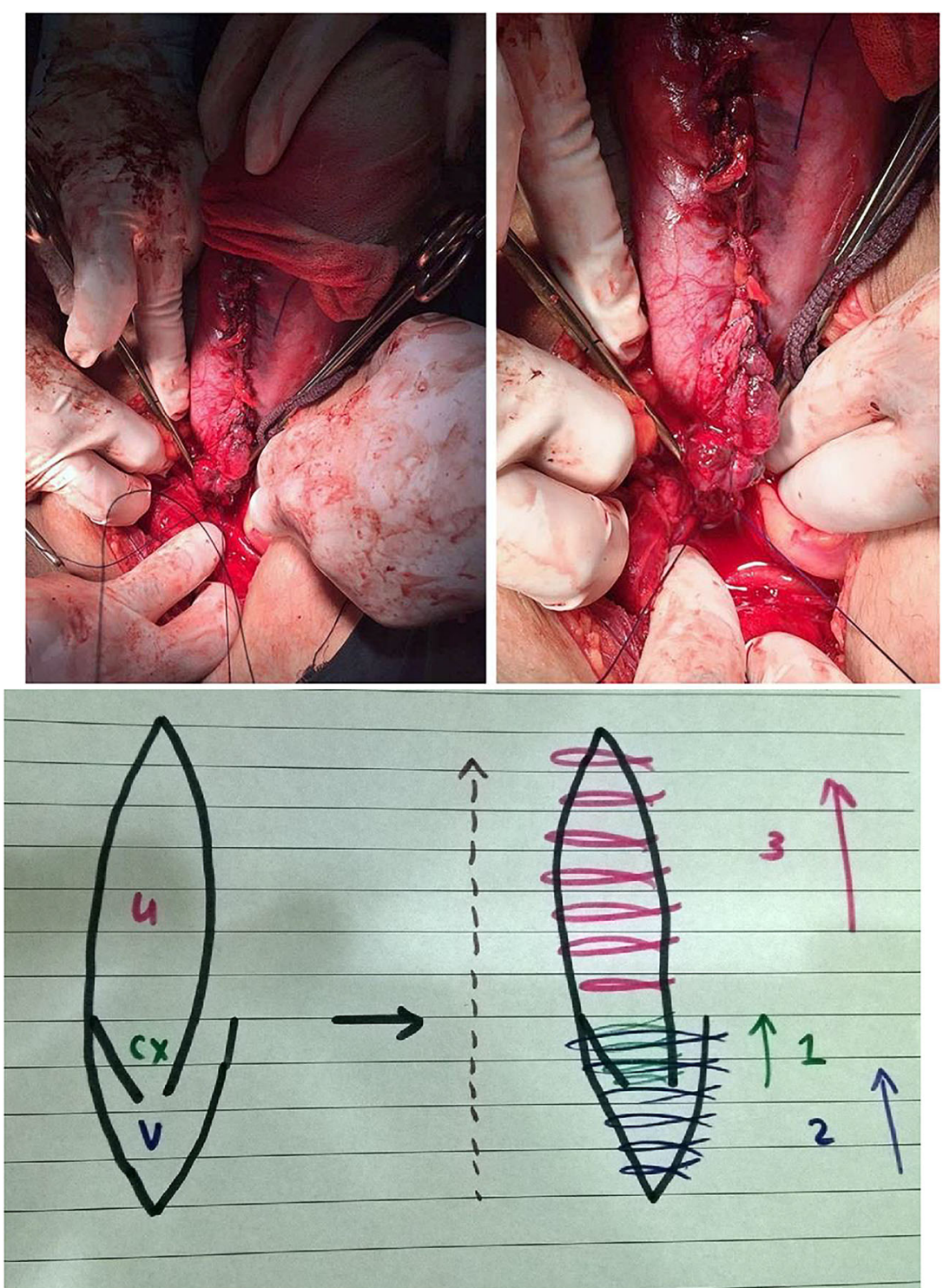

Figure 3 Repair of the vaginal tear over the sutured cervical tear with the ureter identified before vaginal closure (upper photo). Diagrammatic side view of the tear with repair starting from the cervix down up then the vagina then the uterus so as to allow for a space for vagina apex suturing. Usually, the vaginal fornix at that side is obliterated on vaginal examination (lower photo) alternatively, the cervix is sutured then the uterus then the vagina over the sutured cervix .the first technique allows a finger through the cavity during suturing the vagina for no missing a tear in the vagina during suturing 


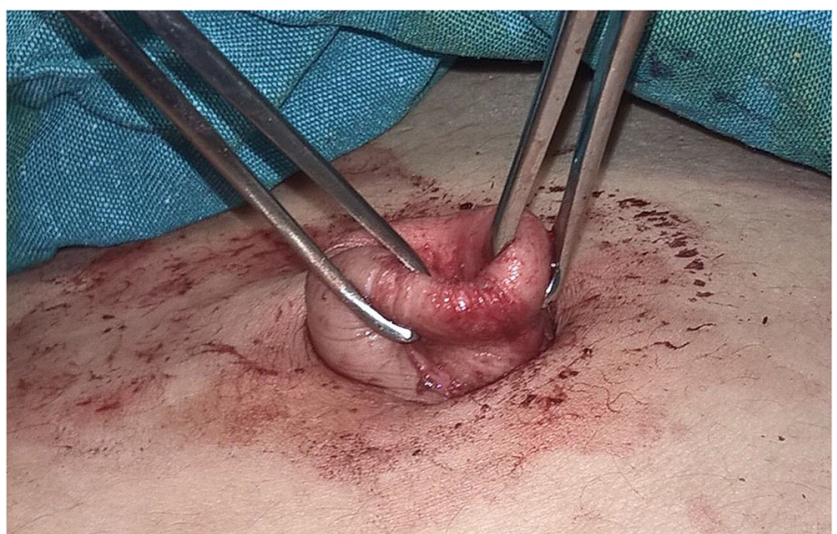

Figure 4. Elevation of the inward umbilical skin by two allis forceps till the base is seen then insert the Veress or the trocar. 